\title{
Disruptive Innovation in Hospitality Human Resource
}

\author{
Basant P. Joshi \\ Head of School \\ School of Hotel Management/Asian Institute of Technology and Management (AITM) \\ Lalitpur, Nepal \\ basantpjoshi@gmail.com
}

\begin{abstract}
In this 21st century, where all the organizational activities are transforming into a digital technology base, the disruption in any business cannot be imagined without adapting a technological breakthrough. Technological disruption in HR may cause a robotic service experience for the customers, especially in the hospitality industry because if the human resource component is replaced with the technology, for e.g. a meal service in the restaurant if replaced with a robotic machine or a robot, the human touch component of that experience will not be realized by the customer hence the service in a long run becomes mechanistic. The innovation theory seems to be more relevant to any product or a service but when we talk about human resource, it is neither a product nor a service. The term Human Resource is used to the people those who work for the organization and also the department who is responsible for managing the required resources for the employees to facilitate their job. The term Human Resource was first coined in the year 1960 when people realized the value of labor relation, motivation, behavior and productivity.
\end{abstract}

Keywords: Digital disruption, human capital, cognitive, affective

\section{Introduction}

Christensen, Raynor \& Mc Donald (2015) defined disruptive innovation as a term in the field of business administration which refers to an innovation that creates a new market and value network, and eventually disrupts an existing market and value network, displacing established market leading firms, products, and alliances. These professors coined the theory of disruptive innovation and have become the most influential idea of the modern age. According to the theory, all innovations are not regarded as the disruptive. For example if we take the example of automobile from late $19^{\text {th }}$ century, this is not a ready example of disruption because these automobiles 
were expensive yet luxury category items and did not disrupt the market for horsedrawn vehicles. The transportation market, stable until the introduction of the lower-priced Ford Model in 1908, the mass produced automobile, was a disruptive innovation because it changed the entire transportation market where as the first three year of automobile did not.

Disruptive innovation has been produced by the new entrants, entrepreneurs, rather than the existing market-leading companies. In the beginning, it is very difficult for the firms to pursue disruptive innovation because they are not profitable enough in the beginning because their development can take scare resources away from sustaining innovations. Disruptive process takes a long time and once it is established, there is a very fast market penetration and the effects of which disrupts the established markets. It is also said that some companies have been identified as the victim of disruption and remain stagnant in the industry today (for example Seagate Technology, U.S. Steel and Bucyrus). There comes a question as if the theory has been misapplied to explain everything in every sphere of life, including not just a business but something like public institutions and the education.

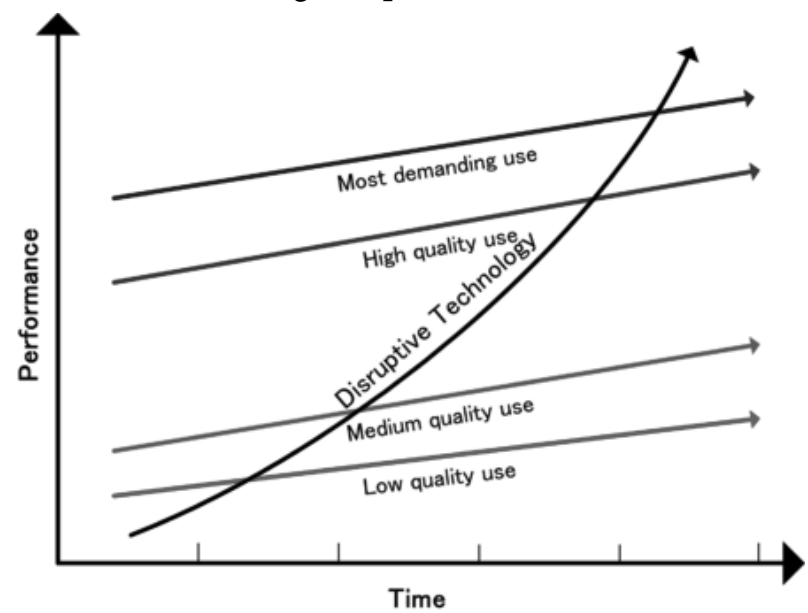

Source: Clayton M., Michael R. and R. McDonald, What is Disruptive Innovation, December (2015)

To call it a really disruptive innovation for any service or the product, it should answer the following questions."

1) Are the entrants targeting a segment that is economically unattractive to incumbents? Relating this question with the disruptive innovation in Hospitality Human Resource, the question becomes like this: Are the entrants targeting the human resource part of the organization which is not productive and significant in the eyes of the previous management settings? 
2) Are the entrants able to serve this segment profitably due to a different business model? Relating to this question to the hospitality human resource, we can put a question: Are the entrants able to serve this segment or motivate the human resource, proficiently and effectively using different techniques?

3) If we can in fact answer "yes" to (2), then we need to know whether or not the smaller firms have an "enabling technology" that will allow them to take on larger, more complex projects using their new business model without sacrificing the cost advantages and performance profile that allowed them to serve smaller projects profitably? That is, can the smaller EPCM firms "March upmarket" without merely turning into the larger EPCM companies that already occupy the mainstream of the market?

If we answer all three questions to "yes" the case we are refereeing is a disruptive innovation and if any of these are not answered, the process is not really a disruptive innovation front.

\section{Literature review}

According to Santen R. and Kirk J. (2016) in an interview of hospitality channel, in the hospitality business, there also exist the disruptive forces in hospitality industry. Obviously, there are new players immerging in the market in a different way forward. For example how guests are finding rooms, how the hoteliers are prepared for that and how the hotels' are maintaining their human resource issues. We need to understand and find the ways that the disruption is going on. So it is also a mindset change to understand that how we do business, is it changing and are we ready to embrace that change. So it's also the human factor and this is also an area we take a lot of focus. Christensen, Raynor \& McDonald (2015) disruptive innovation is not a breakthrough innovation. It is the innovation which creates a different market segment of a historically important and an unaffordable product or service. It is difficult to relate his theory into the human resource management or most commonly known as human capital management of any business especially, the hospitality industry.

The innovation theory seems to be more relevant to any product or a service but when we talk about human resource, it is neither a product nor a service. The term Human Resource is used to the people those who work for the organization and also the department who is responsible for managing the required resources for the employees to facilitate their job. The term Human Resource was first coined in the year 1960 when people realized the value of labor relation, motivation, behavior and productivity.

According to Tracey (2004) Human Resource is "The people that staff and operate an organization," as contrasted with the financial and material resources 
of an organization. A Human Resource is a single person or employee within your organization. According to Thomas (2016) the term disruptive human resource is defined in two folds, the term "Disruptive HR is proactive whereas handling" disruption in HR is reactive. The term disruptive HR, is emerging to meet the global challenges of the disruptive world. Disruptive HR listens and acknowledges the need of job market, talent pool and organizational goals to think out of box and to deliver additional value to themselves and to the organization. However, based on his propagations of this theory to the rest of the world, it can be adapted in the human resource to be taken as a catalytic product which helps in disruption process to happen in any organization. Having said this, it is important to see the disruptive changes in the human resources component and the organizations should see their HR components as how Ritz Carlton Hotels worldwide take care of their HR with the slogan "We take care of those who take care of our valuable customers" This slogan shows that HR component of hospitality business is important factor which can be an agent of change to all the strategic changes we make in our organization.

In this $21^{\text {st }}$ century, where all the organizational activities are transforming into a digital technology base, the disruption in any business cannot be imagined without adapting a technological breakthrough. Technological disruption in HR may cause a robotic service experience for the customers, especially in the hospitality industry because if the human resource component is replaced with the technology, for e.g. a meal service in the restaurant, if replaced with a robotic machine or a robot, the human touch component of that experience will not be realized by the customer hence, the service in a long run becomes mechanistic.

According to Reinke(2016) restaurants thrive because of their human component. They are living art, culinary museums that only exist when people provide a product through thoughtful service. This is why other 'disruptive' technologies have not seen success in the market: they try to remove the human element through the use of iPads, tables or ordering kiosks. But these sorts of models will only achieve initial success in fast-casual settings when the customer is looking to receive food quickly. For those looking for the authentic dining experience, technology will not help a lot. Clothbound's model though, which disrupts the system behind the scenes, is beginning to make its mark. Clothbound is an online platform that connects potential employees with restaurants. Similar to monster.com, it provides a convenient, simple job board specifically for the restaurant industry. Zagat most recently recognized Kelly Daigle, co-founder of Clothbound, in their 30 under 30 list of Boston's finest, acknowledging her innovative thinking and impact on the market. Clothbound's technological platform is bringing the restaurant network to a digital space, effectively bringing together the two networks of employers and their potential staff. 
Reinke (2016) further stresses on the disruptive Human Resource. Disruption capitalizes on improving the efficiency of existing systems as seen with the success in other branches of the hospitality industry: transportation (Uber) and lodging (Airbnb). Uber and Airbnb have achieved remarkable success because their systems capitalize on independence and convenience for the traveler. In both models the customer does not need to rely on a system operated by another party (hotels, hostels, taxis, etc.) but instead can be the captains of their own fate by calling their Uber and booking their dream stay without third-party fees. Even more conveniently, these innovative models are utilized through the use of smart technology and online interactions. Although there are some debates about Uber and Airbnb whether or not being the examples of disruptive innovation. The restaurant, however, cannot exist online, and the successful restaurant is as much experiential as it is product-based. Any adaptation of the restaurant model (pre-ordering, tablets on tables, etc.) have not lasted very long as they tarnish the very essence of a dining experience. A true meal in any self-respecting restaurant is tech-free, engaging, authentic, and sensory.

Disruptive innovation theory has its own limitations. It is successful in many industries but has not been able to relate many other industries. Relating this theory with the Human Resource of Hospitality Industry is the first attempt. Researcher has studied over many written articles, published conference videos, write-ups and interviews of many professionals those who worked in this field and found that such kind of research especially in Hospitality Industry is not done before. Being the first of its kind, it was very difficult to relate Disruptive innovation theory into Hospitality Human Resource because the resources to this context are very much less. This is the reason why, researcher also put his experience of more than a decade working in five star hotels in Nepal and abroad handling thousands of people in Hospitality Industry from operations to academics. Interviews, group discussions, talks and feedbacks of many people in hospitality industry of Nepal are also included in the study.

\section{Disruptive Human Resource Approach}

The term disruptive innovation theory can be adapted in two different levels of the Human Resource Development namely:

Disruption in Human Resource System and Disruption in Human Resource Performance.

\section{Disruption in Human Resource System}

According to Thomas (2016) based on an article of Josh, Bersin of Forbes (2014), following are the innovation in the Human Resource System that has changed the roadmap of the organizational development.

1. Employee System Engagement: Modern managers are replacing the system of traditional office records and creating an employee friendly engagement plan 
in building their own records. Employee, employer interface is a system which is well integrated and has a direct access of the employee to it. All kind of HR records of the particular employee can be viewed by the management and the employee at all the times. This interface facilitates the attendance, notices, financials of the particular employee, performance appraisals, feedbacks (to and fro), leave records, warnings and appreciations in automated control basis. The system is good for the organizations which have qualified employees and has drawbacks for the organizations where the academic levels of the employees are average. Mobile devices are playing an important role in this endeavor.

2. People resourcing strategy: People outsourcing has become much easier with the innovation in global networks and connections. HR professionals are using Linked Inn, Glass door, indeed, and other social media sites for a direct hiring of the employees. Ritz Carlton hotels worldwide which has more than 130 hotels have developed a system of hiring via online through their registered websites. In this process, any deserving hospitality graduate or the employee from any corner of the world can register himself in their employee hiring section and can send his/her details for the available position for the evaluation. After the evaluation, there will be a Skype interview with the panel. After the successful completion of the interview and other formalities, the person will be hired directly.

3. User friendly job portals for employee and employers: Today's HR has become IT friendly. Neither the employees nor the employers need to hunt for each other. There are the job portals available online for both of their purpose. In these job portals, the employee can upload their personal information and similarly, the employers also are available online to tap their required Human Resource.

4. Mobile Applications: According to Kleiner Perkins and Caufeild \& Byers (KPCB) (2016) There are 5.2 Billion mobile users in the world, 1.6 billion smart phone users, $789 \mathrm{~m}$ Laptops, $745 \mathrm{~m}$. desktops

5. Data Driven decisions: According to Deloittee research (2014) only 4\% of the big companies have the ability to analyze, predict and model their human resource but $90 \%$ have the ability to analyze, predict and model their financial structure. Data analysis for employee recruitment, selection, orientation and training and development has no longer been a product; it has become a science based solution. (Thomas 2016)

The results of Thomas (2016). who had made research over 42 private Indian companies found that $85 \%$ of the companies are ready to develop their employees. $43 \%$ of employee's didn't participate in the training and development because it was 
not mandatory. The biggest challenge found was the change management which the companies are not able to. The biggest role models for making such changes in the HR are HR Managers 59\% respondents.

\section{Disruption in Human Resource Performance}

It is important that if something we call a disruptive innovation in human resource, it needs to hit the performance of the employees. Every new entrant should focus on the existing human resource and find the ways how the existing mind set of the employees can be transformed into the most successful innovations. Knowledge, Skill and Attitude (KSA) are the abilities and characteristics that enable a job holder to accomplish the activities described in a task statement that describes what the job holder does (Quinones and Ehrenstein, 1997). In a learning environment, cognitive, psychomotor, \& affective are KSA's counterparts that identify the end states of training (objectives). Disruption in the performance level of the employees can be done in two different levels:

1. The employees, those who are modern, understand the changes, technology, innovations and also understand the competition outside and are career driven we term them explorers. The disruption at this level of staff is known as the explorative disruptive innovation.

2. The employees, who are technically sound but not familiar with the existing competition, are specialized and focused and family driven, we term them sustainers. The disruption at this level can be termed as the sustaining disruptive innovation.

Let us explore the learning outcome typology of Kraiger, et al. (1993). According to the researchers, there are three areas of KSA which are defined as below

- Cognitive (knowledge): This is based of factual and declarative grounds Where the employees are trained on how information and concepts are mentally arranged. This is also defined in terms of metacognitive Strategies allocation and regulation of cognitive resources.

- Skill-Based (psychomotor): This is a development of compilation and automaticity in the employees. Compilation is a routine development and has a procedural linkage. Similarly Automaticity is the ability to perform a task without conscious monitoring and with other tasks.

- Affective (attitudes). This is an attitude in simple terms. Attitude in general understanding is of two different types (positive attitude and the negative). Attitude here is simply the attitude about learning, self-efficacy, perception about ability to perform, and goal setting. The effect of this is related with the motivational disposition of the employees. 


\section{Modern Human Resource in cloud}

Oracle and its affiliates (2015) write disrupting Human capital Management is a new and emerging digital standard. However, the incorporation of the cloud mobile, social big data, and digital consumer experiences into human capital management technology in disrupting how organizations manage enable and engage with their work force. Modern human resource managers are using this a new way of managing people to support an agile work place where people can quickly access knowledge and data to get their jobs done in a purposeful way. With $60 \%$ of the DEO's indicating that cloud computing technology strategically significant to their business. Cloud is fundamentally changing the way organization will do a business in the future. $90 \%$ of the world's population who are over 60 year of old will be using the mobiles by 2020. By the year 2020, the entire generation will have been grown in digital world. Computers, mobile phones, tablets, texting and social networking will be second nature to them.

As the world becoming increasingly volatile and unpredicted, organizations that can quickly and easily adapt to changing business conditions will outpace their competitors.

\section{Case studies from Ritz Carlton and Kempinski Hotel}

Whether or not the Ritz Carlton company in the world which is best known for handing well of its staff knows about the theory of disruption, it is using very much modern technique for handling disruption in Human Resource. Contrary to the theory of disruptive innovation, it is not the new entrant which focuses on disruptive innovation; it is a very old hospitality institution, however working in a modern way in handling its staff and disruption. Ritz- Carlton, a Hotel Company in this category is a leading luxury lodging company famous for its own standards. It is the only service company in USA that has been able the own the MALCOLM Baldridge National Quality Award (MNQA), and the Training Magazine announce it as the only company best known for its training and development for the employees. Reiss R. (2009) further highlights that its unique culture starts with a motto: "We are ladies and gentlemen serving ladies and gentlemen." One of its remarkable policies is to permit every employee to spend up to $\$ 2,000$ making any single guest satisfied. This is not per month rather is per case.

Ritz-Carlton codifies its expectations regarding service in "The 12 Service Values," "The Credo," "The Three Steps of Service," "The 6th Diamond" and other proprietary statements that are taught to all 38,000 employees throughout 73 properties in 24 countries. Simon Cooper, who has led Ritz-Carlton for the past eight years, says about what makes Ritz-Carlton that it basically focuses on the location, the product and the people when it comes the investment. They invest about $\$ 500,000$ and over 
$\$ 1$ million per room for example for a room. Choose the best and convenient location for their costumer so that they get an easy access of the Hotel. Similarly, the ladies and gentlemen serving ladies and gentlemen statement of the company show how much they are focused on the employee development and their moral values.

According to the tradition of Ritz Carlton, they practice a "line up," tradition which is a concept of early restaurants in France where chef calls his team every evening at 5.30pm. Every Ritz Carlton Hotel every day, round the globe has a round table every day where each member has an opportunity to share a "wow story" which means talking great things about their staff have done. This shows a different innovative approach which lots of hotels ignore but Ritz Carlton does for their staff is an example of disruptive innovation. In an interview of Forbes, Reiss R. (2009) further explains that at Ritz Carlton.

1. It entrusts every single Ritz-Carlton staff member, without approval from their general manager, to spend up to $\$ 2,000$ on a guest. And that's not per year. It is per incident. This shows that the trust factor which is instilled in each and every member of the hotel is the significant achievement that the hotel has made while handling the disruption at the motivation level of the employee that generates a good attitude and leads to stability, dedication and productivity.

2. A carpenter is hired for building a shoe rack for the guest for his/her special choice for one night. Similarly, a laundry manager who couldn't get the stain out of a dress after trying twice would fly from Puerto Rico to New York to return the dress personally. This shows that how the employees are motivated. This is a new technique which Ritz applies to let the employees go beyond the box to satisfy their guest and feel accomplished by knowingly or unknowingly is an example of disruptive innovation strategy at HR front.

3. They hire typically about $2 \%$ of the people who apply for jobs. Bringing on the right ladies and gentlemen and then nurturing them to provide them with career opportunities will reduce turnover. Training is really important, because it nurtures the careers of our ladies and gentlemen. Naturally, in a tough economic climate keeping staff satisfied is more challenging, but obviously it's as important as ever.

4. Ritz Carlton measures the voluntary turnover, which is an indicator of the talent acquisition and training. At Ritz Carlton, they typically hire about $20 \%$ of the people who apply for the job to ensure that they hire the right kind of ladies and gentleman and then train them to the best possible career options so that the turnover is very less. The training and development strategy at Ritz Carlton and the low turnover shows that it is able to utilize the disruptive innovative approach at HR level which the competitors not. 
5. At Ritz Carlton, a culture is built on trust. And ifleadership doesn't live the values that it requires of the organization that is the swiftest way to undermine the culture. No culture sticks if it's not lived at the highest levels of the organization. It takes an extraordinarily long time to build a culture. Kempinski makes huge investment in human resource development every year. The company implemented training programs across all levels of staff focused on building management acumen, enhancing technical expertise and operational skills, and cross-training between departments, and intends to continue to build on staff development. In a survey of Cornell University among 243 managers, $64 \%$ of the respondents stressed on the issues of attraction, retention, training and morale as key areas of concern of the managers. This report showed that today's Human Resource is ideally difficult to motivate unless the hospitality companies focus purely on innovations, which their competitors are not able to focus on.

1. Kempinski has a full year calendar for staff training, development and engagement. It fully believes that the staff needs to be fully engaged with the aid of modern techniques and traits. According to Kempinski (2010), Regional Director of Training of Kempenski, Karen Thorburn, who was the winner of the Best HR person of Hotelier Middle East Awards 2009, stated about their success in opening of the properties with the help of staff who are frequently trained and taken off the floor for making them competent enough to handle the competition. They equally focus on explorers and the sustainers as outlined in the study. This shows that disruption is possible via training and development of staff in both explorer and the sustainers' level.

2. Kempinski also employed specialists who travelled the region delivering skills' training programs on making the perfect cup of tea and coffee, and the best bread. These sessions were run in Kempinski properties worldwide. "In this region Kempinski implemented these travelling expert concepts in Tanzania, Djibouti and the UAE finishing with the iconic Emirates Palace in Abu Dhabi.

3. The pilot of the Employee Satisfaction Survey at Kempinski Hotel Ajman further reasserted the company's strong focus on people. The survey was conducted under the theme 'It's all about people'. All employees were invited to participate in the survey, which was held in conjunction with a full schedule of fun activities throughout the day - a buffet lunch, cooking classes, massages, access to the beach for employees and their families, prize competitions, bowling, camel rides, hotel tours and much more. Kempinski is the first in the region with $99 \%$ completion rate on the Employee Satisfaction Survey," 
4. Kempinski has also piloted an E-learning program in English and several management programs. "The feedback has been encouraging. Kempinski has also developed a skills-enhancement program for Housekeeping specifically aimed at career progression of supervisors and assistant housekeepers.

The hospitality industry is long hours and very hands on and there are many things one just does not have the time to learn on the job, such as staff costing, developing budgets, business plans, marketing principles and leadership/ management skills. Providing staff structured pathways to imbibe this information helps them move ahead in their careers, and helps a company progress in levels of service expertise and competitiveness within the industry.

Figure1. Example of Lodging Firms in the Four Areas can be taken as disruptive innovation techniques at HR front

\begin{tabular}{|c|c|c|c|}
\hline $\begin{array}{l}\text { Selective Hiring } \\
\text { and Retention } \\
\text { Strategies }\end{array}$ & $\begin{array}{l}\text { Competency } \\
\text { Training and } \\
\text { leadership } \\
\text { Development } \\
\text { Programs. }\end{array}$ & $\begin{array}{l}\text { Benefits and } \\
\text { incentive plans } \\
\text { to Enhance } \\
\text { Performance } \\
\text { Reduce Costs }\end{array}$ & $\begin{array}{l}\text { Redesigning } \\
\text { Work to Enhance } \\
\text { Employee } \\
\text { Involvement }\end{array}$ \\
\hline $\begin{array}{l}\text { Dahlmar } \\
\text { Properties: } \\
\text { Job Preview } \\
\text { Sessions } \\
\text { Orientation with } \\
\text { Quizzes and } \\
\text { Tests } \\
\text { Ramada } \\
\text { Franchise } \\
\text { systems: } \\
\text { Prescreening } \\
\text { tests Interactive } \\
\text { CD-Based } \\
\text { Training } \\
\text { Ritz Carlton, } \\
\text { Tyson's Corner. } \\
\text { Hourly Staff } \\
\text { Interview and } \\
\text { Selection Team }\end{array}$ & $\begin{array}{l}\text { Coastal Hotel } \\
\text { Group: } \\
\text { Buddy System to } \\
\text { Loan Employees } \\
\text { Four Seasons: } \\
\text { Designed Trainer } \\
\text { Choice Hotels: } \\
\text { Leadership } \\
\text { Competency } \\
\text { Building } \\
\text { Marriott } \\
\text { International } \\
\text { Competency } \\
\text { Building }\end{array}$ & $\begin{array}{l}\text { Accor: } \\
360^{\circ} \text { Feedback } \\
\text { The Houstonian: } \\
\text { All Employees } \\
\text { on a Bonus } \\
\text { System } \\
\text { Roadway INN } \\
\text { ØOrlando: } \\
\text { Budget of } \$ 100 \\
\text { per Month } \\
\text { Awards, Pins } \\
\text { and Gifts }\end{array}$ & $\begin{array}{l}\text { Ritz Carlton- } \\
\text { Tyson's } \\
\text { Corner: } \\
\text { Self-Directed } \\
\text { Work } \\
\text { Teams } \\
\text { The Boulders: } \\
\text { Self -Directed } \\
\text { Three Person } \\
\text { Housekeeping } \\
\text { Teams } \\
\text { Empowered To } \\
\text { Choose } \\
\text { Work Areas } \\
\text { Responsible } \\
\text { For Quality } \\
\text { Conduct Own } \\
\text { Inspections }\end{array}$ \\
\hline
\end{tabular}




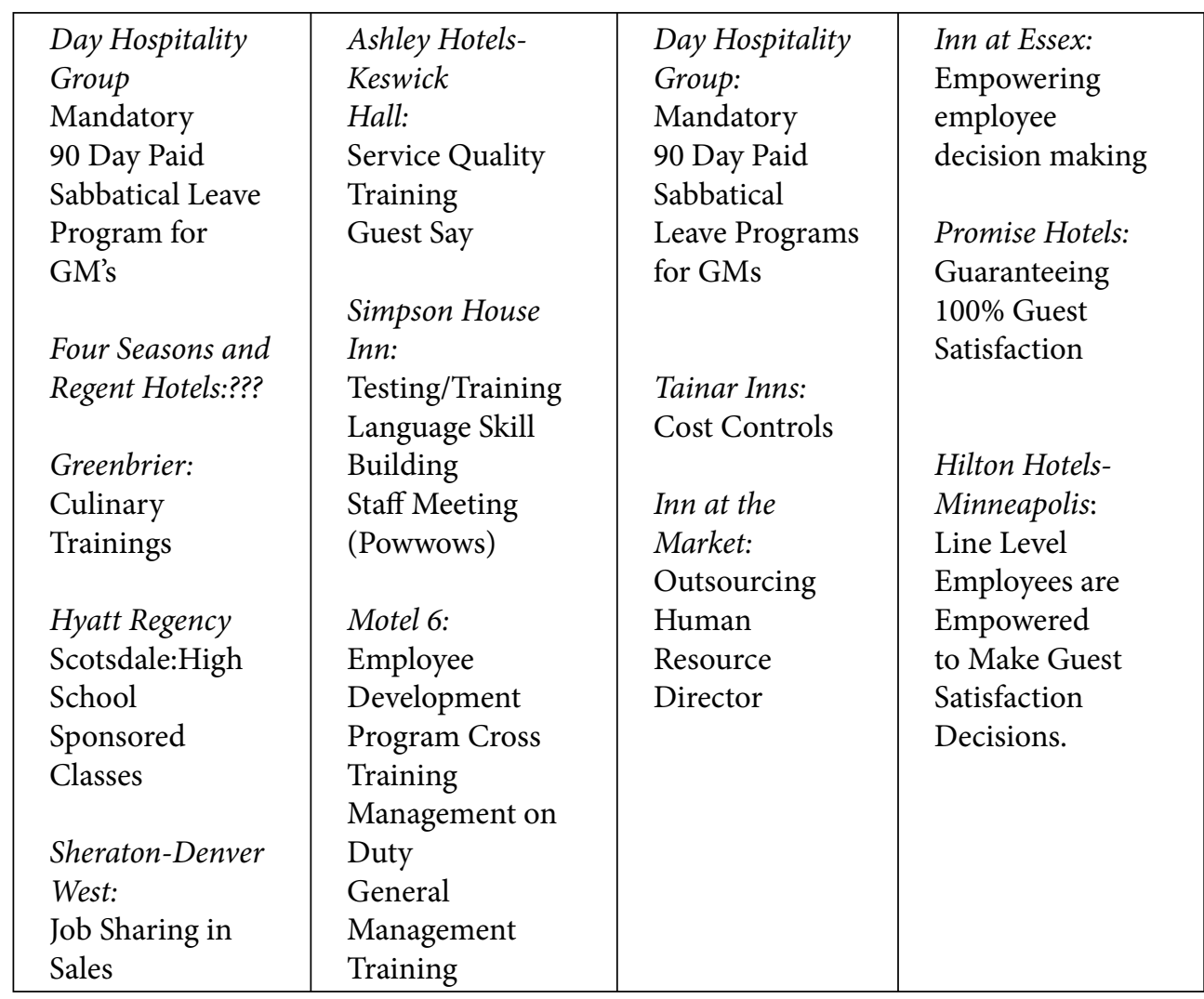

Source: Adapted from, Kate Walch and Cathy A. Innovation in Hospitality Human Resource, 2017

\section{Findings and conclusions from the study}

In this 21 st century, where all the organizational activities are transforming into a digital technology base, the disruption in any business cannot be imagined without adapting a technological breakthrough. Technological disruption in HR may cause a robotic service experience for the customers, especially in the hospitality industry because if the human resource component is replaced with the technology, for e.g. a meal service in the restaurant if replaced with a robotic machine or a robot, the human touch component of that experience will not be realized by the customer hence the service in a long run becomes mechanistic. In a survey of Cornell University among 243 managers, $64 \%$ of the respondents stressed on the issues of attraction, retention, training and morale as key areas of concern of the managers. This report showed that today's Human Resource is ideally difficult to motivate unless the hospitality companies focus purely on innovations, which their competitors are not able to focus on. 
The fundamental input of this study is the finding of the link between the disruptive innovation and the practices in Hotel's Human Resource. Studies of hospitality innovation, especially the radical innovation, are few (Chan et al., 1998, Rodgers, 2007), those that investigate the impact of disruptive HRM practices on hotel industry. It is found that two major HRM practices, hiring dynamic core customer- contact employees which we call multi-skilled employees and training core customer-contact employees for multiple skills, enhanced both incremental and radical disruptive innovation in Hotels. Although "select for attitude and train for skill” has been a very long management philosophy, it is arguable that to enhance the disruptive innovation in hospitality HRM, a better strategy might be "hire for skill and train for skill. "The findings are contradictory with Tracey et al. (2007) conclusions that both general mental ability and consciousness are important factors of front line staff job performance.

The results of Thomas A. who had made research over 42 private Indian companies found that $85 \%$ of the companies are ready to develop their employees. $43 \%$ of employee's didn't participate in the training and development because it was not mandatory, shows that the management should function on making people feel the importance of training and development to handle the disruption. This shows the importance of HR managers' role in handling disruptive innovation in HR. It is also found that the hotels are not openly practicing disruptive innovation theory because of not being able to relate this theory with their day to day operations, especially in HR.

In the study, the focus is on two different areas of Human Resource namely the explorative disruptive innovation and sustaining disruptive innovation. It is found that the disruptive innovation at the lower level of staff who are less qualified in terms of academic qualification but are skillful, need sustaining disruptive innovation techniques, and this ideally fits the theory of Dr. Christensen, which shows that for something to be called a disruptive innovation, it should be emerging from a very distinctive market, which the competitors never touched but ignored, and is profitably handled by new incumbents. Disruption at this level which we call in this paper, sustaining disruptive innovation is what Dr. Christensen and team put forward.

\section{References}

Chan A., Go. F.M., Pine, R. (1998). Service innovation in Hong Kong: Attitudes and practice. The Service Industries Journal 18, 112-124.

Christensen C., Raynor M. \& McDonald, R. (2015). What is disruption: Harvard Business review. Retrieved from: https://hbr.org/2015/12/what-is-disruptiveinnovation\#comment-section

Deloitte (2015). Global Human Capital Trends 2014: Engaging the 21 ${ }^{\text {st }}$ Century Work Force. Retrieved from: https://www2.deloitte.com/content/dam/ 
Deloitte/ar/Documents/human-capital/arg_hc_global-human-capital-trends2014_09062014\%20(1).pdf

Disruptive innovation. Wikipedia 2017. Retrieved from: https://en.wikipedia.org/ wiki/Disruptive_innovation

Kempinski (2010). Worldwide Recruitment / Job / Training, Press release published on 2010-01-07. Retrieved from: https://www.luxury-hospitality-daily.com

Kraiger K., Ford J. \& Salas E. (1993). Application of cognitive, skill-based, and affective theories of learning outcomes to new methods of training evaluation. Journal of Applied Psychology, 78, 311-328.

Learning: Knowledge, Skills, and Attitudes (KSA) retrieved from: http://www.nwlink. com/ donclark/learning/ska.html

Oracle and its affiliates (2015). Modern HR in Cloud. Disrupting Human Capital Management: The new emerging digital standards of HR. Retrieved from: file://D:/ PERSONAL/PHD\%20AIU\%20USA/DISRUPTIVE\%20INNOVATION/digitaldisruption-2665262.pdf

Quinones M.A. and Ehrenstein A. (1997). Training for a Rapidly Changing Workplace: Applications of Psychological Research. Washington, D.C.: American Psychological Association, p. 154.

Reinke M. (2016), Disruption from the inside-out: Innovation in the restaurant industry. Boston Hospitality Review. Boston University School of Hotel administration, 4(1).

Reiss R. (2009). Forbes, Retrieved from https://www.forbes.com/2009/10/30/simoncooper-ritz-leadership-ceonetwork-hotels.html\#3fa3db3a10b1.

Rodgers, S., 2007. Innovation in food service technology and its strategic role. International Journal of Hospitality Management 26, 899-912.

Santen R. V. and Kirk J. (2017). Disruptive innovation in hospitality. Retrieved from the video: http://hospitality channel.com/video/disruptive-innovation-inhospitality.

Tracey J.B., Sturman M.C., \& Tews. M.J.(2007). Ability versus personality: Factors that predict employee job performance. Cornell Hotel and Restaurant Administration, Quarterly 48, 313-322.

Tracey W. R. (2004). The Human Resource Glossary: The complete desk reference for HR Managers, Executives and practitioners. St. Lucie Press. USA 